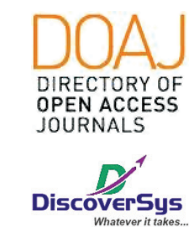

Published by DiscoverSys

\section{Overview of drugs used for the treatment of hypertension for elderly patients in Sanglah General Hospital, Denpasar, Bali}

\author{
Archana Laxmi Pathmanathan, ${ }^{1 *}$ I Nyoman Gede Wardana, ${ }^{2}$ I Gusti Ayu Widianti, ${ }^{2}$
}

\section{ABSTRACT}

Background: Hypertension is one of the most common diseases among elderly patients and it is also known as a silent killer. It could be due to excessive stress which causes the blood pressure to rise. The symptoms could appear, and people could go on for years without having any awareness of their disease.

Aim: This research was conducted to determine the prevalence of hypertension cases of elderly patients and the drugs used as a treatment for hypertension in Sanglah Hospital, Denpasar, Bali. The research was carried on in the Sanglah Hospital, Denpasar, Bali as of January until June 2017.
Method: In this study, a descriptive cross sectional study method was being used.

Result: As the age increases, the number of individuals with hypertension increases. In gender, we could see that the female has a higher prevalence compared to male. In Sanglah, we found that the mostly given drugs are amlodipine and captopril for elderly people as this drug works effectively for the patients. Other drugs such as valsartan, furosemide, and bisoprolol are also offered to patients with hypertension depending on their associated diseases.
${ }^{1}$ Medical Science Study Program, Medical Faculty, Udayana University

${ }^{2}$ Department of Anatomy, Medical Faculty, Udayana University

${ }^{*}$ Corespondence to: Archana Laxmi Pathmanathan, Medical Science Study Program, Medical Faculty, Udayana University archanalaxmi2308@gmail.com

Received: 2018-04-08 Accepted: 2018-08-09 Published: 2019-08-01

Keywords: Hypertension, treatment, awareness, drugs

Cite This Article: Pathmanathan, A.L., Wardana, I.N.G., Widianti, I.G.A. 2019. Overview of drugs used for the treatment of hypertension for elderly patients in Sanglah General Hospital, Denpasar, Bali. Intisari Sains Medis 10(2): 184-187. D0I: 10.15562/ism.v10i2.215

\title{
INTRODUCTION
}

Hypertension is a prevalent condition worldwide and contributes major risk factor for cardiovascular diseases. Mortality from stroke and ischemic heart disease doubles with the increase of each $20 \mathrm{~mm} \mathrm{Hg}$ in systolic blood pressure (SBP) from levels as low as $115 \mathrm{~mm} \mathrm{Hg}$, and with the increase of each $10 \mathrm{~mm}$ $\mathrm{Hg}$ in diastolic blood pressure (DBP) from levels as low as 75 mm Hg. ${ }^{1}$

Hypertension is one of the highest ranked chronic diseases in elderly people. It is either primary hypertension or secondary hypertension. The reason of primary hypertension is not known, the factor that affect blood pressure regulation are now being studied, even though genetic and environmental factors are said to be the factors. Secondary hypertension the main types are chronic kidney disease, renal artery stenosis, excessive aldosterone secretion, pheochromocytoma, and sleep apnea. This secondary hypertension can be identified and can be treated sometimes. It is very rare where about 5\% of adult only have this secondary type. ${ }^{2}$ Blood pressure is normally measured by either a conventional sphygmomanometer utilizing a stethoscope or by an electronic device. The electronic device, if accessible, is favored because it gives more reproducible outcomes than the more established strategy and is not impacted by varieties in the system or by the predisposition of the spectators. The auscultatory strategy is utilized the first and fifth Korotkoff sounds. It is the appearance and vanishing of sounds compared to the systolic and diastolic blood weights.

There are two sorts of treatment should be possible for patients with hypertension. One is a nonpharmacologic way and another way is medical treatment. The nonpharmacologic way is used for non-extreme cases, similar to stage 1 with no relationship with another severe cardiovascular disease; sometime they should begin their medical treatment. However when there is no any movement in the blood pressure for around six months after the way of life change, then it is unequivocally prescribed to continue with medical treatment. The way of life changes that is as specified above are, for example, weight reduction, salt decrease, practice consistently, constrained liquor utilization and quit smoking. This would help in decreasing the blood pressure. ${ }^{3}$

Angiotensin-Converting Inhibitors (ACE), these operators decrease blood pressure by obstructing the renin-angiotensin framework. The principal symptom is hacked particularly for ladies. These medications build serum creatinine, however, as of the diminishing pressure inside the renal glomerulus and reduction filtration. Angiotensin receptor blockers (ARB), like angiotensin-converting enzyme inhibitors, threaten the renin-angiotensin framework. Angiotensin receptor blockers can expand serum 
creatinine, yet as common this is a practical change that is reversible and not hurtful. Try not to combine angiotensin receptor blockers with angiotensin-converting inhibitors, each of these medication sorts is helpful in patients with kidney disease, yet in the mix, they may effectively affect renal occasions. ${ }^{4}$

Thiazide and Thiazide-like Diuretic are specialists work by expanding discharge of sodium by the kidneys and may have some vasodilator impacts. It benefits from lessening of strokes and major cardiovascular occasions. The fundamental symptoms of these medications are metabolic (hypokalemia, hyperglycemia, and hyperuricemia). Calcium Channel Blockers agents reduce blood pressure by blocking the inward flow of calcium ions through the L channels of arterial smooth muscle cells. The main side effect of calcium channel blockers is peripheral edema. Nondihydropyridine calcium channel blockers are not recommended in patients with heart failure, but amlodipine appears to be safe when given to heart failure patients receiving standard therapy with ACE inhibitors. The dihydropyridine, but not the nondihydropyridine, agents can be safely combined with $\beta$-blockers. ${ }^{5}$

$\beta$-blockers reduce cardiac output and also decrease the release of renin from the kidney. They have strong clinical outcome benefits in patients with histories of myocardial infarction and heart failure. Their main side effects could reduce sexual function, fatigue, and reduced exercise tolerance. a-Blockers reduce blood pressure by blocking arterial $\alpha$-adrenergic receptors and thus preventing the vasoconstrictor actions of these receptors. ${ }^{6}$

For hypertension without other convincing signs, diastolic with or without systolic hypertension with those over 60 years Thiazide/thiazide-like diuretics, ACE inhibitors, ARBs, or long-acting CCBs (consider ASA and statins in chose patients) as the underlying treatment and mix of first-line drugs treatment for second-line therapy. For patients with cardiovascular disease, patients with $\mathrm{CAD}$ or recent myocardial infarction $\mathrm{ACE}$ or $\mathrm{ARB}$ and $\beta$-blockers for the first line. Long-acting $\mathrm{CCB}$ at the point when combined treatment is being utilized for high-chance patients for CAD second line and long-acting CCBs if $\beta$-blocker contraindicated for myocardial infarction. For heart failure patients, ACE inhibitors (ARBs if ACE inhibitor-intolerant) and $\beta$-blockers. Aldosterone antagonist (mineralocorticoid receptor antagonist) might be included for the first line.

\section{METHODS}

In this particular survey conducted, a descriptive cross sectional was designed to determine the total number of hypertension patient with age above 55 years old and the drug used for treatment among patients in Sanglah Hospital, Denpasar, Bali. This study involves the target population of people diagnosed with hypertension that are elderly in Sanglah Hospital Denpasar, Bali.

Research data is based on the secondary data that will be collected from the Medical record in Sanglah General Hospital, Denpasar, Bali. The investigator collects the data of hypertension patients who are elderly from the hospital from January until June 2017.

\section{RESULTS}

\section{Characteristics of the sample}

In Sanglah the total number of patients with hypertension in 6 months had 173 and there are only 96 patients with above 55 years old. According to the data collected and had been divided into few characteristics such as age, gender, classification, stages, and drugs. Table 1 shows the total number of patients divided into their components and the percentage.

The hypertension case is in the age group of 55-64 and 65-74. Where out of total 96 patients with hypertension 76 of them are from the age group of 55-64 and 65-74. We could find as the age increases the number of individuals with hypertension increases too. Out of the total 96 elderly patients with hypertension 45 were males and 51 were females. It shows that women have a higher rate of having hypertension at the elderly age than men.

However, elderly patients in Sanglah Hospital it shows that most individuals have primary hypertension which could be caused by an unknown cause. There is no proper study shows whether which stage 1 or stage 2 hypertension are prominent among elderly patients, but it is important to identify the types of hypertension to provide proper management. ${ }^{7}$

Based on the table above, captopril been used to treat 23 elderly hypertensive patients, amlodipine been used to treat 13 patients, valsartan been used to treat 8 patients, furosemide been used to treat 5 patients, combination of captopril and amlodipine been used on 21 patients, combination of valsartan and amlodipine been used on 11 patients, combination of furosemide and amlodipine been used on 3 patients and combination of bisoprolol and captopril been used on 12 patients. Based on the above findings, captopril has been used in mono-therapy as the most while the combination of captopril and amlodipine been used the most in combination therapy. 
Table 1 Characteristic of the samples

\begin{tabular}{|c|c|c|}
\hline Elderly patients with hypertension & Total $(n=96)$ & Percentage (100\%) \\
\hline \multicolumn{3}{|l|}{ Age (range) } \\
\hline $55-64$ & 46 & 48 \\
\hline $65-74$ & 30 & 31 \\
\hline $75-84$ & 13 & 14 \\
\hline$>85$ & 7 & 7 \\
\hline \multicolumn{3}{|l|}{ Gender } \\
\hline Males & 45 & 47 \\
\hline Females & 51 & 53 \\
\hline \multicolumn{3}{|l|}{ Classification } \\
\hline Primary Hypertension & 64 & 67 \\
\hline Secondary Hypertension & 32 & 33 \\
\hline \multicolumn{3}{|l|}{ Stages } \\
\hline One & 59 & 61 \\
\hline Two & 37 & 39 \\
\hline \multicolumn{3}{|l|}{ Drugs } \\
\hline Captopril & 23 & 24 \\
\hline Captopril + Amlodipine & 21 & 22 \\
\hline Amlodipine & 13 & 14 \\
\hline Bisoprolol + Captopril & 12 & 13 \\
\hline Valsartan + Amlodipine & 11 & 11 \\
\hline Valsartan & 8 & 8 \\
\hline Furosemide & 5 & 5 \\
\hline Furosemide + Amlodipine & 3 & 3 \\
\hline
\end{tabular}

\section{DISCUSSION}

According to National Center for Health Statistics (US) Health, United States (2007), as our population ages, the importance of cardiovascular disease (CVD) as the leading cause of death in adults becomes increasingly apparent. One major reason for this trend is the patterns of blood pressure changes and increased hypertension prevalence with age (about 1 billion people worldwide). According to National Centre of Health Statistics (2014), hypertension prevalence is less in women than in men until 45 years of age, is similar in both sexes from 45 to 64 and is much higher in women than men over 65 years of age. The severity of hypertension increases markedly with advancing age in women as well. After the period of 60 years, the majority of women (age 60-79 years: $48.8 \%$; age $\geq 80$ years: $63 \%$ ) has stage 2 hypertension (BP $\geq 160 / 100 \mathrm{mmHg}$ ) or receives antihypertensive therapy.

The diagnosis of hypertension should be based on at least 3 different BP measurements taken on $\geq 2$ separate office visits. The majority of cases are due to primary hypertension. However, it is important to identify correctable causes of hypertension also known as secondary hypertension. History and examination may give clues to the presence of an underlying disease such as renal failure, renovascular disease, hyperaldosteronism, pheochromocytoma or Cushing syndrome. Other suggestive factors are lack of family history of hypertension, unusual course, early complications or resistance to therapy. ${ }^{2}$

Based on what we have discussed earlier in this paper, stage 1 hypertension reading for systolic is $140-159 \mathrm{~mm} \mathrm{Hg}$, or the diastolic reading is 90-99 $\mathrm{mm} \mathrm{Hg}$. Last but not least, the final stage which is known as stage 2 has a reading of systolic more than $160 \mathrm{~mm} \mathrm{Hg}$ or diastolic more than $100 \mathrm{~mm} \mathrm{Hg}$. When systolic and diastolic pressure falls into different categories, the higher category should be selected in classifying the individual's blood pressure status.

The JNC-8 trial recommends a thiazide, ACE, ARB, CCB alone as initial drug therapy or in combination with other class. Thiazide diuretics control hypertension by inhibiting reabsorption of sodium $\left(\mathrm{Na}^{+}\right)$and chloride $(\mathrm{Cl})$ ions from the distal convoluted tubules in the kidneys by blocking the thiazide-sensitive $\mathrm{Na}^{+}-\mathrm{Cl}^{-}$symporter. However, in Sanglah Hospital, the total elderly hypertension patients from January to June 2017 are 96, and only 5 people are given furosemide as initial thiazide diuretics.

ACE inhibitors can also be considered for firstline or combination therapy, especially if diabetes, HF, post-myocardial infarction or chronic disease is present. ACE inhibitors block the conversion of angiotensin I to angiotensin II in multiple tissues and thus lower total peripheral vascular resistance reducing $\mathrm{BP}$ without reflex stimulation of heart rate and cardiac output. In Sanglah Hospital, captopril which is an ACE inhibitor been used for 23 patients out of 96 which is the most used anti-hypertension drug. As mentioned above ACE inhibitors can be used as a first line or for combination therapy. In Sanglah Hospital captopril and amlodipine been used as the highest in the combination therapy which is for 21 patients.

Hypertensive patients with diabetes mellitus, angiotensin receptor blockers (ARBs) are considered first-line treatment and as an alternative to ACEIs in patients with hypertension and HF who cannot tolerate ACEIs. Blockage of angiotensin II receptors directly causes vasodilation, reduces secretion of vasopressin and reduces production and secretion of aldosterone. Based on the study made in Sanglah Hospital, Valsartan which is an angiotensin receptor blocker, been used to treat 8 elderly hypertension patients.

The usefulness of $\beta$ blockers (reduce the heart rate and cardiac output, inhibit renin release, 
generate NO, reduce vasomotor tone) as first-line treatment of hypertension in older persons has been questioned. Although $\beta$-blockers have been used for hypertension in the elderly for years, evidence for benefit has not been convincing. The National Institute for Health and Clinical Excellence in the United Kingdom has advised the use of $\beta$-blockers as a fourth antihypertensive agent since it has a lot of side effects. In this study, bisoprolol which is a $\beta$-blocker didn't use as a monotherapy. However, the combination of bisoprolol and captopril been used on 12 patients.

In general, calcium antagonists appear well tolerated by the elderly. They are a heterogeneous group of drugs with different effects on heart muscle, sinus node function, atrioventricular conduction, peripheral arteries and coronary circulation. The Syst-Eur study shows that antihypertensive treatment with a calcium channel blocker could reduce cardiovascular complications in elderly patients with isolated systolic hypertension. In this study, amlodipine which is a calcium channel blocker been used on 13 elderly hypertension patients. It is also been used as the most in combination therapy in Sanglah Hospital.

Both 2009 updated ESH/ESC and the ACCF/ AHA 2011 Expert Consensus Document on Hypertension in the Elderly recommend the combination of 2 drugs to be considered as initial treatment whenever hypertensive patients have high initial BP or are classified as being at high cardiovascular risk. Trial evidence of outcome reduction has been obtained particularly for the combination of a diuretic with an ACE inhibitor or an angiotensin receptor antagonist, and in recent trials for the ACE inhibitor/calcium antagonist combination been effective where we could see in the study in Sanglah Hospital that the combination of captopril and amlodipine been used the most. It enhanced efficacy, reduced adverse effects, improved compliance as well as potential organ protection are the key benefits of the combination therapy.

\section{CONCLUSION}

As from January until Jun 2017 there were 173 in total patients that had been diagnosed with hypertension, and 96 of them are elderly which are 55 years old above, in Sanglah Hospital, Denpasar, Bali. Other than that, the age group of 55-64 has the highest range of people with hypertension which are $48 \%$. Hypertension among elderly slightly dominated by the females. The difference between males and female are not much which are about $47 \%$ and $53 \%$.

Furthermore, primary hypertension is higher compared to secondary hypertension in elderly patients in general as it is familiar. Stage 1 or Stage 2 is not prominent, but according to our data collection, the Stage 1 hypertension is higher among the elderly. The stages need to be determined due to treatment. Moreover, captopril which is an ACE Inhibitor, been used as the most in monotherapy. Combination of calcium channel blocker and ACE Inhibitor which is amlodipine and captopril respectively, been used as the most in combination therapy of hypertension.

\section{ACKNOWLEDGMENT}

The authors might want to extend their warm appreciation to the Almighty God for showering them with great wellbeing and the wellspring of astuteness and information to put the needs right to finish this paper in the dispensed time. Next, their affirmation toward the Medical Faculty of Udayana University, Denpasar for giving them the chance to enhance their focus on degree and expand the enthusiasm into the excellent point of the elective study, hypertension and the medication that is used to treat hypertension in elderly patients.

\section{REFERENCES}

1. Crim,M.,Yoon,S.,Ortiz,E., Wall,H.,Schober,S.,Gillespie,C., Sorlie, P., Keenan, N., Labarthe, D. and Hong, Y. National Surveillance Definitions for Hypertension Prevalence and Control Among Adults. Circulation: Cardiovascular Quality and Outcomes. 2012; 5(3): 343-51.

2. Lionakis, N., Mendrinos, D., Sanidas, E., Favatas, G. and Georgopoulou, M. Hypertension in the elderly. World Journal of Cardiology. 2012; 4(5): 135-147.

3. Flack, J., Sica, D. and Nesbitt, S. Chlorthalidone Versus Hydrochlorothiazide as the Preferred Diuretic: Is There a Verdict Yet?. Hypertension. 2011; 57(4): 665-666.

4. Weber, M., L. Schiffrin, E., B. White, W., Mann, S., H. Lindholm, L., G. Kenerson, J., M. Flack, J. and L. Carter, B. Clinical Practice Guidelines for the Management of Hypertension in the Community A Statement by the American Society of Hypertension and the International Society of Hypertension. The Journal of Clinical Hypertension. 2014; 16(1): 14 - 26.

5. Schäfer, H., Kaiser, E., and Lotze, U. Increasing complexity: which drug class to choose for treatment of hypertension in the elderly?. Clinical Interventions in Aging; 2014: 459.

6. Dasgupta, K., Quinn, R., Zarnke, K. and M. Rabi, D. The 2014 Canadian Hypertension Education Program Recommendations for Blood Pressure Measurement, Diagnosis, Assessment of Risk, Prevention, and Treatment of Hypertension. 2014; 30: 485 - 501.

7. McDonald, M., Hertz, R., Unger, A. and Lustik, M. PCV21 Prevalence Awareness and Management of Hypertension, Dyslipidemia, and Diabetes amongUnited Stated Adults Aged 65 and Older. The value in Health. 2008; 11(3): A192.

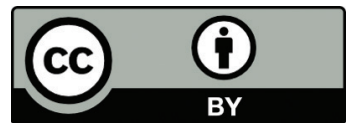

This work is licensed under a Creative Commons Attribution 